\title{
Effect of Leadership, Job Satisfaction, Organizational Commitment to Turnover Intentions of the Companys Employees Outsourcing the in Goods Distribution of Manufactured Good
}

\author{
Daman Sudarman', Nurliana ${ }^{2}$, Anjar Gumelar ${ }^{3}$ \\ DoctoralProgramin ManagementScience, UniversitasPadjajaranBandung,Indonesia \\ damansudarman47@gmail.com¹,nurliana861@gmail.com², contactanjar@gmail.com.33
}

\begin{abstract}
The purpose of this paper is to examine the relationship between leadership, job satisfaction, organizational commitment to turnover intentions through case analysis in one of the outsourcing companies in Indonesia operating as a third party in the distribution of manufacturing goods. A standardized questionnaire were developed. At the same time, the hypothesis was evaluated using census, and distributed to 40 employees. Several analytical techniqueswere used to analyzed the relationship between variables using SPSS 21. The findings of this study provide information that all variables that researchers used, simultaneously and partially affect employee turnover intention. This study contributes to Indonesia's implementation in terms of organizing the distribution of goods manufacturedusingoutsourcing.
\end{abstract}

Keywords: Leadership, Job Satisfaction, Company Commitment, Turnover Intention

\section{Introduction}

The business world is now required to create a higher company for the company's development, in which the company must build and improve the organization's performance. One important factor is human resources because human resources are all top-level planning for resources that utilize other resources needed by the organization or company.More effective marketing management of the products a nd services the organization offers (Owusu-Frimpong, 1999), using third parties is a strategy used by many manufacturing companiesto market their products, so that manufacturing activists remain focused on their core business, without having to think about the way they market their products. Nonetheless, this is currently not feasible, many outsourcing drivers are unable to provide their customers with the best service, and the subtle changes in the business climate require organizations to respond appropriately and rapidly from the outset (Sohi, 1996; Prager, 2003). to provide successful products and services not only depends on employee contact-employee performance and satisfaction, leadership, and employee job satisfaction (Lund, 2003; Yiing and Ahmad, 2009); in Indonesia, there is still not much research on the process of outsourcing that runs the process of distributing goods.

Researchers are motivated to close this gap by beginning to use outsourcing (outsourcing) of Indonesia's increasingly popular business world, which has become a requirement that business actors can not hesitate. However, current regulations are not enough to control outsourcing that is already underway. 


\subsection{Leadership is an Essential Factor for Employee Job Satisfaction and Organizational Success}

Leadership as per each perspective and aspects of the phenomenon (Yukl: 2001: 2), and Stogdill (1974: 259) states that "there are almost as many definitions of leadership as there are people who have tried to define concepts." whereas Karmel (1978: 476) states that "due to the difficulty of defining the meaning of leadership, researchers define leadership as the process of influencing organized group activities towards achieving goals.

Bouradas, 2005; Schyns et al., 2009; Yiing and Ahmad, 2009). Lok and Crawford (2004) and Chang and Lee (2007) argue that leadership aims to manage employee behavior to achieve job satisfaction. While Cam Caldwell: 2012 believes that a leader is a great leader, articulating a vision and integrating meaningful relationships between normative values and the results play a role in achieving the organization's mission, identifying the contribution of the goal-setting process and the results of the goals as an essential part of the leader's role in helping the organization to achieve unprecedented advantages. Creating an effective measurement system for evaluating organizational results is also explained as a tools to help organizational members to focus their efforts as they strive to achieve their organizational mission and to develop their individuals abilities.

\subsection{Job Satisfaction}

Luthans (1998) defines that job satisfaction is a positive and pleasant emotional state of a person, resulting from the assessment of a job or work experience. The five models of job satisfaction, proposed by Kreitner \& Kinichi (2005), are; First, the fulfillment of needs, this model explains a job that satisfaction determined by the job characteristics that allows someone to meet their needs. Second mismatches, this model explains that satisfaction is results from a fulfilled expectation.

Keith Davis (2005: 117) also defined that job satisfaction is " the favorableness or unfavorableness with employees view their work " meaning a good or bad feeling felt by employees at work. Wexley and Yuki (2005: 117) define job satisfaction as "is the way an employee feels about his job." that job satisfaction is the way employeesfeel themselvesor their work, while job satisfaction is considered as a global feeling about work (Vakola and Bouradas, 2005; Wan, 2007; Sahinidis and Bouris, 2008; Fitcher and Cipolla, 2010; Cho et al., 2012; Pantik et al., 2012; Yucel and Bektas, 2012). Locke (1969: 316) defines job satisfaction as "a pleasant emotional status resulting from the assessment of one's work as achieving or facilitating one's work

\subsection{Turnover intention}

Turnover intention is a very important issue for any organization. This happens a lot and becomes an obstacle in conducting of any business, because it relates to the attitude to be taken by an employee, due to various antecedents. Job satisfaction seems to be a good predictor of turnover intention (Chen, 2006; Alniacik et al., 2011). Tett and Meyer (1993: 262) define turnover as "the person terminating one's employment with a particular company," and they also determined turnover intentions as "the last in the order of withdrawal cognition, a collection which is assumed to end and which also includes the purpose of seeking alternative jobs." from many researchers who suggest that, the intention to move is a psychological desire to leave the Organization (Tett and Meyer, 1993; Griffeth et al., 2000; Ohana and Meyer, 2010; Alniacik et al., 2011; Panatik et al., 2012). It is worth to mention that Beadles et al. (2000) and Watrous et al. 
(2006) classify employee turnover as functional, if the employee is performing poorly, or dysfunctional if the employee performs well.

\subsection{Company Commitment}

Porter et al. (1974: 604) defines organizational commitment as "the relative strength of an individual's identification with involvement in a particular organization." Mowday et al. (1979: 226) defines organizational commitment as "active relationships with organizations in such that individuals are willing to give something of themselves to contribute to organizational wellbeing." Organizational commitment is a psychological state that reflects a sense of shared values, identity, loyalty, support, and pride felt by staff members towards their organization (Kim et al,, 2005; Le Rouge et al.,2006; Aghdasiet al..,2011; Cho et al.,2012). Organizational commitment has a sense of ownership, trust, acceptance, and desire to pursue organizational goals, activities, and values, a willingness to stay (less likely to leave) and devote themselves to offer their best efforts for the welfare of their organization (Porter et al., 1974; Mowday et al., 1979; Mowday et al., 1982; Gold and Veiga, 2008; Yang and Chang, 2008; Alniacik et al., 2011; Yamaguchi, 2012; Yucel and Bektas, 2012). Meyer and Allen (1991) argue that there are three types of organizational commitment: sustainability, affective, and normative.

Hrebiniak and Alutto (1972: 556) define continuity commitment as "structural phenomena that occur as a result of individual-organizational transactions and batch-side changes or investments over time." Mowday et al. (1982: 27) define affective commitment as 'the relative strength of the identification and involvement of individuals in a particular organization.' Normative commitment reflects a feeling of obligation to continue work. The concept of organizational commitment is closed to Meyer and Allen (1991: 67) definition of affective commitment "employee emotional attachment to, identification with, and involvement in the organization." Furthermore, employees of an organizational that commit to eff ectiveness perform better (Aghdasi et al., 2011). This was further confirmed by various researchers who conceptualized organizational commitment as an affective attachment to the organization as a consequence of individuals who shared organizational values, their desire to remain in the organization, and their values of willingness to exert efforts on behalf of the organization (Porter et al ., 1974; Mowday et al., 1979; Meyer and Allen, 1991; Meyer et al., 1993; Alniacik et al., 2011; Zeinabadi and Sa lehi, 2011; Yucel and Bektas, 2012). Satisfied, and committed with a little declaration of any intention to leave the organization than those who have a lower level of affective organizational commitment

\subsection{Job Satisfaction and Company Commitment}

Although extensive literature is available about job satisfaction and organizational commitment, The relationship between these two constructs is still under discussion because there are still some critical issues that are considered controversial (Armutlulu and Noyan, 2011). There are two approaches; the first is job satisfaction as an antecedent of organizational commitment; in other words, Staff members' perspectives on their jobs established before their viewpoints on the organization (Yucel and Betkas, 2012). Mowday et al. (1979: 226) state that "employees tend to have strong beliefs and acceptance of organizational goals and values." Furthermore, Rutherford et al. (2009) state that there is a positive relationship between several factors of job satisfaction, such as overall job satisfaction, satisfaction with supervision, satisfaction with salary and organizational policies, and organizational support and commitment. Paulin et al. (2006) proposed that job satisfaction affects organizational commitment, the higher the 
job satisfaction, the greater the organizational commitment. Kim et al. (2005) argue that high employee satisfaction with work has a higher level of organizational commitment than employeeswho are dissatisfied with work. Besides, Morbarak et al. (2006) and Wu and Norman (2006) suggested that there is a reciprocal and positive relationship between job satisfaction and organizational commitment. Also, Moser (1997) and Alniaik et al. (2011) argue that job satisfaction is vital so that often nothing leads to reduced organizational commitment. Various researchers argue that job satisfaction will develop faster than organizational commitment because commitment is a "psychological bond" with the organization, and job satisfaction is more a response to a particular job. Thus job satisfaction is considered as an antecedent of organizational commitment (Zeinabadi, 2010).

\subsection{Job Satisfaction, Organizational Commitment and Intention}

Various researchers emphasize the importance of understanding the antecedents (the causes) and consequences (effects) of job satisfaction because they have essential effects on organizational commitment, turnover intentions and can influence human resource policies and practices(Armutlulu and Noyan, 2011). Mueller and Price (1990) empirical examination for the antecedents of turnover intentions show that job satisfaction is correlated less strongly with turnover intentions than with organizational commitment. Besides, the path of analysis shows that job satisfaction does not directly affect the intention to move. Michaels and Spector (1982) conclude that a lack of job satisfaction and organizational commitment increases the likelihood of employee turnover intentions and, consequently, increases. Several studies have identified job satisfaction and organizational commitment as the main antecedents of turnover intentions (Porter et al., 1974; Ohana and Meyer, 2011). However, it is still unclear, which is the most crucial predictor of shifting intentions (Armutlulu and Noyan, 2011; Alniaik et al., 2011; Gieter et al., 2011). Initial comprehensive empirical research conducted by Porter and Steers (1973) and Muchinsky and Tuttle (1979) show a negative relationship between job satisfaction and employee turnover intention. Also, evidence shows that there is a negative relationship between job satisfaction and the desire to move. In general, the longer employees remain in their jobs, the stronger they report higher levels of job satisfaction, the lower the level of turnover intentions, on the other hand, the higher the level of job dissatisfaction the higher the intention to leave the organization for other work conditions (Aghdasi et al., 2011; Alniacik et al., 2011; Kim and Brymer, 2011; Yuceland Bektas, 2012),

\section{Research Methodology}

The quantitative approach was chosen in this study because this study conducted to explain, to examine the relationship between variables, and this research utilizes a questionnaire as an instrument that generates numerical data for statistical techniques. This study uses a nonprobability sampling technique. Because the sampling process does not provide equal opportunities for each individual, the sampling quota used to determine the sample size is 40 outsourced employees in the operational distribution of Indonesian manufactured goods. Hypothesis testing in this study is to use SPPS 21. 


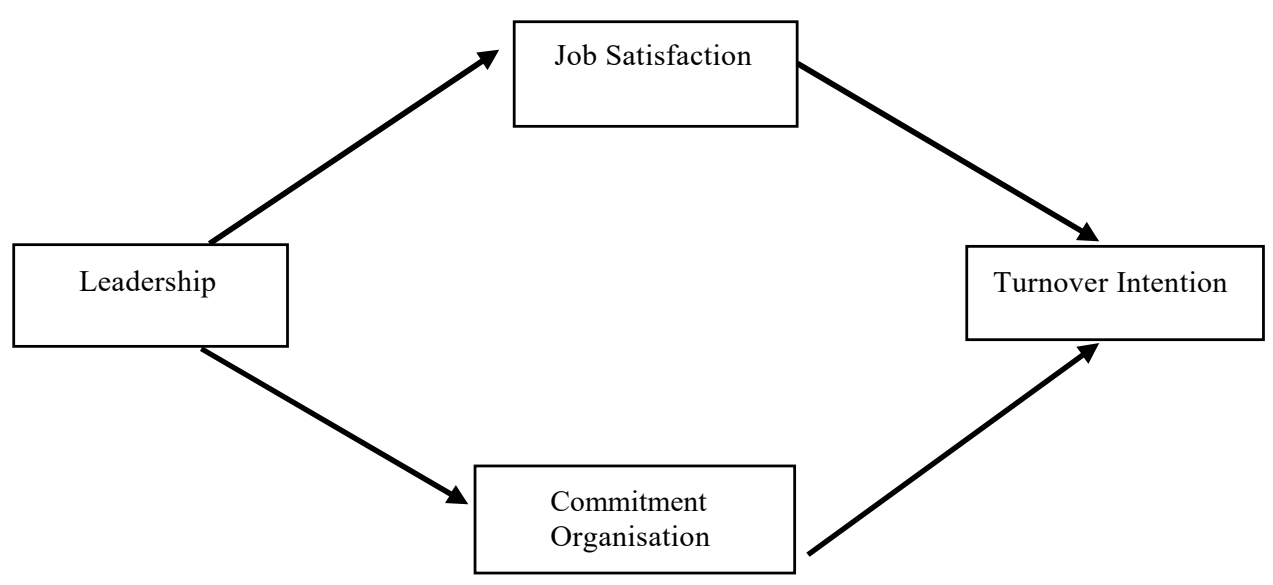

Fig.1. Model of riset

\section{Results and Discussions}

This study uses a questionnaire that contains 20 question items. The validity and reliability of this questionnaire are proven. This questionnaire was distributed to 40 employees outsourcing the distribution of manufactured goods in Indonesia.

Tabel 1. Path analysis of leadership variables, Job Satisfaction, turnover intentions, organizational commitment to turnover intentions

\begin{tabular}{|c|c|c|c|c|c|}
\hline \multirow[t]{2}{*}{ Model } & \multicolumn{2}{|c|}{$\begin{array}{l}\text { Unstandardized } \\
\text { Coefficients }\end{array}$} & \multirow{2}{*}{$\begin{array}{c}\text { Standardized } \\
\text { Coefficients } \\
\text { Beta }\end{array}$} & \multirow[t]{2}{*}{ t } & \multirow[t]{2}{*}{ Sig. } \\
\hline & B & Std. Error & & & \\
\hline \multirow[t]{2}{*}{ (Constant) } & 6.800 & 4.492 & & 1 & \\
\hline & & & & .514 & 138 \\
\hline \multirow[t]{2}{*}{ Leadership } & .636 & .083 & .703 & 7 & \\
\hline & & & & .647 & 000 \\
\hline \multirow[t]{2}{*}{ Job Satisfaction } & -.061 & .072 & -.073 & - & \\
\hline & & & & .858 & 36 \\
\hline \multirow[t]{2}{*}{ Comitmen organization } & .640 & .080 & .554 & 7 & \\
\hline & & & & .959 & 000 \\
\hline
\end{tabular}

a. Dependent Variable: TurnoverIntention

Table 2. Correlation analysis of leadership variables, Job Satisfaction, turnover intentions, organizational commitment to turnover intentions

\begin{tabular}{|c|c|c|c|c|}
\hline \multicolumn{5}{|c|}{ Correlations } \\
\hline & $\begin{array}{c}\text { Job } \\
\text { Satisfaction }\end{array}$ & Leadership & $\begin{array}{c}\text { Comitment } \\
\text { Organization }\end{array}$ & $\begin{array}{l}\text { Turnover } \\
\text { Intention }\end{array}$ \\
\hline Pearson Comitment Organization & 1.000 & .830 & .177 & .001 \\
\hline
\end{tabular}




\begin{tabular}{|c|c|c|c|c|c|}
\hline & & $\begin{array}{c}\text { Job } \\
\text { Satisfaction }\end{array}$ & Leadership & $\begin{array}{c}\text { Comitment } \\
\text { Organization }\end{array}$ & $\begin{array}{l}\text { Turnover } \\
\text { Intention }\end{array}$ \\
\hline \multirow[t]{3}{*}{ Correlation } & Leadership & .830 & 1.000 & 294 & .036 \\
\hline & Job Satisfaction & .077 & .094 & 1.000 & .023 \\
\hline & Turnover Intention & .567 & .436 & .223 & 1.000 \\
\hline \multirow{4}{*}{$\begin{array}{l}\text { Sig. (1- } \\
\text { tailed) }\end{array}$} & Comitment Organization & . & .000 & .312 & .000 \\
\hline & Leadership & .000 & . & .274 & .002 \\
\hline & Job Satisfaction & .312 & .274 & .221 & .075 \\
\hline & Turnover Intention & .000 & .002 & .075 & .000 \\
\hline \multirow[t]{4}{*}{$\mathrm{N}$} & Comitment Organization & 43 & 43 & 43 & 43 \\
\hline & Leadership & 43 & 43 & 43 & 43 \\
\hline & Job Satisfaction & 43 & 43 & 43 & 43 \\
\hline & Turnover Intention & 43 & 43 & 43 & 43 \\
\hline
\end{tabular}

The results of the calculation of the path analysis of the influence of leadership on company commitment and job satisfaction on turnover intention Obtained the coefficient va lues as follows: The path coefficient value of leadership influence on turnover intention is 0.703 , and the correlation coefficient value is 0.036 , at a significant level of the table of 0.000 . Because $0,000<$ 0.05 (significance level of 5\%), it can be said that the structural model is valid, so there is an effect significant between leadership on turnover intention, the path coefficient value of the influence of organizational commitment to turnover intention is 0.554 and the co rrelation coefficient value is 0.001 , at a significant level of the table of 0,000 . Because $0,000<0.05$ (significance level of 5\%), it can be said that the structural model is declared valid, so there is a significant effect between organizational commitment to turnover intention, while the path coefficient value of job satisfaction on turnover intention is 0.554 and the correlation coefficient value is 0.036 , at a significant level of the table at 0.000 . because $0.036<0.05$ ( tin significance level of $5 \%$ ), it can be said that the structural model is declared valid, so there is a significant effect between job satisfaction on turnover intention.

\section{Citations}

Employees learn ethical standards that can be accepted by organizationsby observing their leaders' actions and behavior (Kim and Brymer, 2011). Ethical leadership is more than good behavior; it is a crucial factor that contributes to the long-term success of the organization. Leaders who are fair, caring, open, sincere, and honest play an essential role in increasing employee job satisfaction. Develop self-efficacy to achieve their job roles can make differences for organizational. Furthermore, the alignment between employee goals and consistent expectations of researchers, found that there is a positive and significant relationship between affective commitment and employee job satisfaction and positive, but not significant between affective commitment and intention to move. Contrary to researchers' expectations, a negative and significant relationship founded between normative and continuing commitment and employee satisfaction and positive, but not significant between normative and continuing commitment and intention to move.

A possible reason for this result is that there is a mismatch between employees' experiences before entering and during work in terms of family culture and organizational socialization, but they are emotionally bound. Organizations must direct towards right hiring decisions with candidates who value customer satisfaction and service quality excellence and tra ined 
intensively to improve their technical and social skills. It is not surprising to find an inadequate organizational commitment and intention to move. The main reason they damage the property of a business is that they are not aware of how to use managerial tools to achieve high performance and fulfill their goals and objectives. Overall, such an organization will not achieve the goals, objectives, and effectivenessof the organization.

\section{References}

[1] Alniacik, U.; Cigerim, E.; Akein, K.; Bayram, O., (2011), "Independent and joint effects of perceived corporate reputation, affective commitment and job satisfaction on turnover intentions", Procedia - Social and Behavioral Sciences, Vol. 24, pp. 1177- 1189.

[2] Armutlulu, I. H.; and Noyan, F. (2011), "A multilevel of organizational commitment", Procedia Social and BehavioralSciences, Vol.30, pp.2139-2143..

[3] Arnold, T.; Flaherty, K. E.; Voss, K. E.; Mowen, J.C., (2009), "Role Stressors and Retail Performance: The Role of Perceived Competitive Climate", Journal of Retailing, Vol.85, pp. 194-205

[4] Brown, A. D. and Humphreys, M. (1996), "International cultural differences in public sector management: Lessons from a survey of British and Egyptian technical education manager", International Journal of Public Sector Management, Vol. 8 No. 3, pp.5-23..

[5] rown, S.P and Peterson, R.A. (1993), "Antecedents and consequences of salesperson job satisfaction: meta-analysis and assessment of causal effects", Journal of Marketing Research, Vol. 30, pp. 63-77.

[6] Cameron, K. S., and Freeman, S.L. (1991), "Cultural congruence strength and type: relationship to effectiveness", Research in Organisational change and Development, Vol. 5, pp.23-58.

[7] Cameron, K.S., and Quinn, R.E. (1999), Diagnosing and changing organisational culture: based on the competing values framework. Reading, MA: Addison-Wesley.

[8] Carless, S.A. (2005), "Person-job fit verses person-organisation fit as predictors of organisational attraction and job acceptance intentions: A longitudinal study", Journal of Occupational Psychology, Vol. 78 (September),pp. 411-429..

[9] Chang, S.C.; Lee, M. S.; (2007),"Astudy on relationship among leadership, organizational culture, the operation of learning organization and employees' job satisfaction", The Learning Organization, Vol. 14, No. 2 pp. $155-185$

[10] Chen, C. F., (2006), “Job satisfaction, organizational commitment, and flight attendants' turnover intentions: A note", Journal of Air Transport Management, Vol. 12, pp. 274- 276

[11] Cho, Y.N; Rutherford,B. N.; Park, J.K.(2012), "The impact of emotionallabor in a retail environment", Journal of Business Research, Under press.

[12] Denison, D. (1990). Corporate culture and Organisational effectiveness, Wiley and Sons, New York.

[13] Deshpande', R., Farley, J. U., and Webster, F. E. Jr. (1993), "Corporate culture, customer orientation, and innovativeness in Japanese firms: A Quadrad Analysis", Journal of Marketing, Vol. 52 (January), PP. 3-15.

[14] M. Bharti, "Impact of Dimensions of Mobile Banking on User Satisfaction,” J. Internet Bank. Commer., vol.21, no. 1,pp. 1-22,2016.

[15] Deshpande', R, and Webster, F. E. Jr. (1989), “organizational culture and marketing: defining the researchagenda", Journal of Marketing, Vol.53, January, pp. 3-15..

[16] Erdogan, B., and Bauer, T. N. (2005), "Enhancing career benefits of employee proactive personality: the role of fit with jobs and organisations", Personal Psychology, Vol. 58 No. 4, pp.859-891.

[17] Evans, M.G. (1970), "The effects of supervisory behaviour on the path-goal relationship", Organisational Behaviour and Human Performance, Vol.5, pp.277-298. 